\section{History of the radiological health program of the Pan American Health Organization ${ }^{1}$}

\author{
Gerald P. Hanson, ${ }^{2}$ Cari Borrás, ${ }^{3}$ \\ and Pablo Jiméne ${ }^{4}$
}

Key words: delivery of health care, radiologic health, radiology, radiation protection, radiotherapy, Pan American Health Organization, Americas.

\footnotetext{
1 A more extensive version of this article will be available on the PAHO website (www.paho.org).

2 Former Regional Advisor in Radiological Health for the Pan American Health Organization, Washington, D.C., United States of America. Send correspondence to: Dr. Gerald P. Hanson, 2 Winterberry Court, Bethesda, Maryland 20817, United States of America.

3 Former Regional Advisor in Radiological Health for the Pan American Health Organization, Washington, D.C., United States of America.

4 Current Regional Advisor in Radiological Health for the Pan American Health Organization, Washington, D.C., United States of America.
}

The radiological health program of the Pan American Health Organization (PAHO) was established in 1960. Although the program has undergone various organizational changes, it continues to operate to this date. It has been operational through the administrations of five of the Directors of the Pan American Sanitary Bureau (PASB), which is PAHO's Secretariat, and has been located in various PAHO divisions or areas of work. Its program emphasis has evolved with the requirements of the Member States of PAHO. However, the program has essentially remained a unit with activities in research, training, radiation protection, and services in the areas of public health and clinical medicine.

\section{9-1975, PASB DIRECTOR ABRAHAM HORWITZ}

In the 1950s the world superpowers were actively engaged in a nuclear arms race and were testing weapons in the atmosphere. Governments and people throughout the world were deeply concerned about the effects of worldwide radioactive fallout. Civil defense shelters were being constructed to protect against such fallout and against nuclear blasts, and schoolchildren were being taught to deal with a nuclear attack. Also, the peaceful uses of atomic energy were being promoted, and radioisotopes were being developed for diagnosis, research, and therapy.

In 1960, PAHO established the Radiological Health Unit, with two professionals and a secretary, to promote the role of public health authorities in the field of applied nuclear energy. The head of the Unit was Regional Radiological Health Advisor Irvin Lourie, a physician who was supported by Specialized Technical Advisor Thomas Shea, a health physicist.

The 1960 Annual report of the Director of the PASB (1) stated that the program of the Radiological Health Unit would be directed along four main lines: (1) stimulating national health services to develop procedures for regulations governing the use of X-rays and radioisotopes and the disposal of radioactive wastes, based on the recommendations of the International Commission on Radiological Protection; (2) promoting the teaching of basic health physics and radiological protection in schools of medicine, dentistry, public health, veterinary medicine, etc.; (3) fostering the use of radioiso- 
topes for medical diagnosis, therapy, and research, and (4) encouraging research on applications of radiation that might be of importance to medicine, public health, or veterinary medicine.

In 1962 the XVI Pan American Sanitary Conference approved a research policy for PAHO and requested that the Director of the PASB "take all possible steps to expand the research activities of the Organization, including specific projects and their financing, for the mutual benefit of the countries of the Region [of the Americas]" (2). In 1962, PAHO established the Advisory Committee on Medical Research (ACMR). This had a stimulating effect on the research aspects of PAHO's technical programs, including radiological health.

In collaboration with physicist Merrill Eisenbud of New York University (NYU), preliminary studies were performed of food, water, and human teeth from the areas of Brazil with a high natural radiation background. Later, a conference was held to elucidate the public health significance of background radiation, and financial support for the Biophysics Institute of the University of Brazil and the Catholic University of Rio de Janeiro to conduct biological and physical studies was obtained from the Atomic Energy Commission of the United States of America. During the course of the project, numerous Brazilian scientists received training in Brazil and at New York University, and valuable information concerning chronic exposure in areas of high natural radiation background was obtained. PAHO continued to support this project until the end of 1975. By then, development, such as paved roads and building construction, had changed the character of the area.

In Chile a coordinated research project on manganese poisoning in miners was initiated, with collaboration between the Brookhaven National Laboratory, for biochemical analysis, and the School of Medicine of the Catholic University of Chile, for clinical evaluation. Initiated in 1962, the project continued through 1974 . It resulted in an understanding of the biochemical basis of action of various amino acids in chronic manganese poisoning and in Parkinson's disease.

In 1962 and 1963, plans were made to study the effects of irradiation at high altitudes on large animals (burros and llamas). In November 1964, a meeting was held in Lima, Peru, to develop a research project. The altiplano (highland plateau) of Peru was selected as a natural laboratory environment to determine if hypoxia exerts a protective influence by reducing the number of cases of aplastic anemia following high doses of gamma radiation, as well as to study the central nervous system syndrome. It was envisaged that this information might contribute to a better understanding of the development of leukemia in humans.
Over the 1960-1964 period, the Radiological Health Unit also directed efforts toward such other areas as: (1) providing fellowships for training PAHO staff and national professionals, (2) preparing Spanish-language translations of training materials (manuals, pamphlets, slides, movies) and disseminating these materials, (3) promoting radiation control legislation and regulations and establishing national programs, (4) providing advice to governments concerning radiation exposure and control, (5) assisting governments in obtaining international support and arranging scientific collaboration, and (6) representing PAHO at international conferences and meetings.

A program for the radiological surveillance of air and milk in Latin America and the Caribbean was in operation from 1962 to 1981 . At the end of 1976 this program was reevaluated. Subsequently, in collaboration with the School of Public Health of the University of Texas, a program to measure environmental radiation exposure using thermoluminescent dosimeters was organized. By 1981, interest in environmental surveillance had waned. A final report was prepared, and all activities were terminated.

By 1963, PAHO Regional Radiological Health Advisor Lourie was disappointed that it had not been possible to establish a single national radiation protection program within the health ministries. He felt it was imperative to assign a staff member to the field. Specialized Technical Advisor Shea did not wish to leave the Washington, D.C., area and resigned from PAHO.

In December 1964, PAHO recruited Gerald Hanson, a 28-year-old engineer, to be Regional Advisor in Radiation Protection. Hanson had master's degrees in sanitary engineering and in radiological health from the University of Michigan, as well as practical experience as a radiation control program director for the state of Kansas and as a radiation safety officer for a federal government laboratory in the United States.

Stationed in Lima, Peru, Hanson was responsible for providing advice and establishing radiation protection programs within the health ministries of the countries of Latin America and the Caribbean. During the 1965-1968 period, Hanson made numerous visits to countries that had requested technical advice. The topics covered included identification of sources of radiation; radiation protection surveys in hospitals, medical centers, and industries; drafting of legislation and regulations; organizing radiation protection services, including film dosimetry laboratories; training of national staff, including the identification of potential leaders for fellowship support; setting up and operating fallout monitoring programs; pro- 
moting and coordinating research; and coordinating activities with national and international radiation protection agencies.

A training team was formed by appointing two consultants: Jorge Roman, an occupational health engineer from Peru, and Robert Bostrom, a training specialist from the U.S. Public Health Service (USPHS). Using excellent training materials (the Basic science review and the Basic manual on radiation protection) that had been prepared in collaboration with the USPHS, short courses were presented in various countries.

In mid-1967, PAHO Regional Radiological Health Advisor Lourie felt he had no alternative but to resign. He had made the strongest case possible for increasing the resources available to the PAHO radiological health program, but was informed by the Director that no additional funds or staff would be assigned. From that point onward, until Jorge Litvak, a Chilean endocrinologist with training in nuclear medicine, joined PAHO in 1969, the program was implemented by the unit's secretary, (Rida Luellsdorf), in Washington, D.C., and Regional Advisor Hanson, now stationed in Santiago, Chile.

By the end of 1968, 10 countries had signed formal agreements with PAHO for assistance in establishing a radiation protection program within their health ministries. These countries were Argentina, Bolivia, Brazil, Chile, Colombia, Costa Rica, Guyana, Jamaica, Uruguay, and Venezuela. In the radiological fallout surveillance program, 12 stations in 10 countries were in operation, with all 12 forwarding daily air samples and 6 sending weekly to monthly composite milk samples. Also, with cooperation from the U.S. Atomic Energy Commission, six radiological health scientific libraries, with several hundred volumes each, were established. They were located in Argentina, Bolivia, Brazil, Chile, Colombia, and Venezuela.

In 1968 a seminal meeting on dosimetric requirements in radiotherapy centers, took place in Caracas, Venezuela, with participation from the International Atomic Energy Agency (IAEA), PAHO, and the World Health Organization (WHO). The recommendations of the meeting included three key items: (1) preparation of a basic manual on dosimetry adapted to Latin American needs, (2) organization of Regional training courses in radiotherapy physics, and (3) creation of Regional dosimetry laboratories. On several occasions in 1969 and 1970, PAHO invited a physicist, John Massey of the Christie Hospital in Manchester, United Kingdom, and a radiation oncologist, Mayer Zaharia of the National Cancer Institute in Lima, Peru, to PAHO Headquarters in Washington, D.C. Those two experts worked with Litvak on the man- ual on dosimetry. When finished, the manuscript, including its Spanish translation, was handed over to the IAEA, and the world-renowned Manual of dosimetry in radiotherapy (the "Massey Manual") was published in 1970, bearing the logos of the IAEA, PAHO, and WHO (3).

In 1970 a Regional course for physicists specializing in radiotherapy was presented at the Puerto Rico Nuclear Center, jointly sponsored by PAHO and the IAEA. Similar courses were held in 1973 in Mexico and in 1975 in Brazil and Chile.

Following PAHO's recommendation, in 1969 WHO established the first Regional Reference Center for Secondary Standard Dosimetry (SSD) within the laboratories of the Atomic Energy Commission of Argentina. For many years this laboratory, and others throughout the world (including ones established within the Nuclear Energy Commission of Brazil and the Health Ministry of Mexico), received funding from WHO. The periodic newsletter of the Secondary Standard Dosimetry Laboratories (SSDLs) was published by WHO from 1970 until 1986, at which time the IAEA took over the responsibility. By the end of 2005 there were 81 SSDLs in 64 countries, and 13 of these laboratories were located in 13 different countries of the Americas.

Also arising out of the 1968 meeting in Caracas was the postal IAEA/WHO program for the intercomparison of radiation therapy doses, using thermoluminescent dosimeters (TLDs). Two physicists serving with the IAEA, Paul Pfalzner of Canada and Robert Loevinger of the United States, had devised a simple method for measuring the radiation dose from cobalt- 60 teletherapy units by using capsules containing thermoluminescent powder that could easily be transported through the mail. PAHO and WHO immediately grasped the impact that such a system could have on improving the practice of radiation therapy, and they joined with IAEA to organize this service on a worldwide basis. From its inception in 1969 through the end of 2005, approximately 2200 measurements (radiation-beam checks) in 330 hospitals or radiation therapy centers in 24 countries in the Americas were made. Since 1991, this has included measurements on linear accelerators. The results of the TLD program-now known as postal dose audits-are described in an article by Iżewska et al. in the current issue of this journal (4).

Participation in the 1968 Caracas meeting cemented Hanson's resolve to obtain training in medical physics. While conducting radiation protection surveys in hospitals and training national staff for this purpose, he was shocked by the lack of support for radiological physics. The hospital physicist was practically nonexistent, with probably no more than a dozen medical radiation physicists working 
in hospitals in all of Latin America and the Caribbean (2 in Argentina, 5 in Brazil, 1 in Colombia, 1 in Jamaica, and 3 in Mexico). In contrast, in 2006 the International Organization for Medical Physics had around 600 members from 11 countries of Latin America and the Caribbean.

The PASB Director allowed Hanson a twoyear leave of absence to obtain his doctoral degree at the University of California in Los Angeles (UCLA). Subsequently, Jorge Litvak was invited to take the vacant post of Regional Advisor in Radiological Health in Washington, D.C. Jorge Roman was appointed to the post of Regional Advisor in Radiation Protection in Santiago, Chile. During 1969 and 1970, Litvak and Roman worked as a team, PAHO's program continued, and a general model for radiation protection legislation was prepared. In these two years a record number of 18 fellowships was awarded for radiological health studies to officials from Argentina, Barbados, Bolivia, Brazil, British Honduras, Chile, Colombia, Costa Rica, Ecuador, Jamaica, Peru, Trinidad and Tobago, and Venezuela.

The team of Litvak and Roman did not continue beyond the first months of 1971. Roman's contract was not renewed, and soon afterward Litvak returned to Chile. By April 1971, Hanson had completed his doctoral studies at UCLA and was assigned to PAHO Headquarters.

The Radiological Health Unit entered into an era of close cooperation with the PAHO Cancer Unit and, in collaboration with the national cancer authorities of Brazil, a study group meeting on the training of personnel in Physics Applied to Radiotherapy was held in Rio de Janeiro in 1972. Radiation oncologists, physicists, and cancer specialists from the Region met with PAHO staff and consultants to develop a plan to satisfy the need for radiotherapy physics services. PAHO invited Carlos Eduardo de Almeida, a young Brazilian student who was pursuing a degree in medical physics at the University of Texas' M. D. Anderson Hospital in Houston, Texas, to attend the meeting as a consultant. Subsequently, de Almeida made a significant contribution to the development of medical physics and radiation protection in the Region of the Americas.

In 1973, PAHO provided to the Government of Haiti a special type of cobalt-60 teletherapy unit called JANUS that had been designed by Ulrich Henschke, a radiation oncologist. With PAHO's support, Henschke and his colleagues provided operational assistance and training in radiation therapy.

The PAHO Radiological Health Unit also began working closely with the Pan American Development Foundation (PADF), and donations of used equipment were offered to countries in the Americas. PADF relied on PAHO's technical advice in deciding whether to accept the offers. During this period PAHO also learned about a revolutionary new diagnostic $X$-ray machine. Richard Chamberlain, a diagnostic radiologist at the University of Pennsylvania, who had developed the machine, named it the "Technamatic."

In the latter part of 1973 the vacant post of Regional Advisor in Radiological Health was filled. The Radiological Health Unit had a new chief, Godofredo Gomez Crespo, a physician from Spain, who had been the regional advisor in the WHO Regional Office for the Eastern Mediterranean. From 1974 to 1979 , both the regional advisor in radiological health and the regional advisor in radiation physics were stationed in Washington, D.C. Gomez Crespo devoted his efforts mainly to diagnostic radiology, nuclear medicine, and radiation therapy. Hanson worked in radiation protection, environmental surveillance, and support for radiation therapy, including the Postal TLD Intercomparison Program.

Soon after becoming the chief of the PAHO Radiological Health Unit, Gomez Crespo was introduced to Chamberlain and immediately recognized the utility of the Technamatic X-ray machine that Chamberlain had developed. The Unit's two regional advisors organized a pivotal working group meeting, held in March 1975 at PAHO Headquarters in Washington, D.C., on planning and developing radiological facilities. Chamberlain, who was terminally ill, participated vigorously, along with experts from Europe, Latin America, and the United States, including Thure Holm, a diagnostic radiologist from Sweden who was an expert on $\mathrm{X}$-ray equipment. The working group developed a diagnostic radiology system for primary care centers, including the specifications for a simple X-ray machine that could operate under adverse conditions. The working group also developed designs for appropriate X-ray rooms and plans for the training of radiology personnel. A year later, Philip Palmer, a diagnostic radiologist from the University of California in Davis who had also attended the March 1975 meeting, wrote a manual that provided the information needed to establish an X-ray department in a small hospital. PAHO published the text (5) in both English- and Spanish-language editions in 1978.

\section{5-1983, PASB DIRECTOR HECTOR ACUÑA}

Hector Acuña became the Director of the PASB in 1975. One of his first priorities was reorganizing the institution. The Radiological Health Unit became part of the Environmental Health Division, 
where it remained until 1979. Within the Environmental Health Division, the country-level projects dealing with air pollution, industrial hygiene, and radiation protection were consolidated within the Division's core program of water supply and waste water disposal. Within a few years, in most countries the country-level budget assigned for the entire environmental engineering program was less than the previous budgets for either industrial hygiene or radiation protection activities alone. During the 1970s, PAHO had made bilateral agreements with several Latin American and Caribbean governments to establish radiological protection programs. When the agreements reached the end of their timeframe, they were not renewed, and by 1977, none of the country radiation protection projects remained.

During his years in the Environmental Health Division, the Regional Advisor in Radiological Health continued to promote the primary care radiology system (PCRS) and the training of technologists. A prototype machine loaned by the University of Pennsylvania was tested for three months in El Salvador in 1975, and a report on that was presented at the Second International Symposium on the Planning of Radiological Departments, held in Philadelphia, Pennsylvania, United States, in 1976. Information concerning curricula in technologist training programs was obtained through visits to various countries, and in 1976 a meeting of directors of schools and programs in X-ray technology training was held in Caracas, Venezuela.

In the radiation protection area, continuing support was provided to the national programs through visits by the Regional Advisor in Radiation Physics and the Regional project's resources, because country projects had declined. The concept of incorporating the emerging activity of quality assurance into national programs was promoted, as were the radiation protection aspects of facility planning; quality assurance in diagnostic radiology, nuclear medicine, and radiation therapy; and the maintenance of radiological equipment. Contact was maintained with international organizations, such as the International Commission on Radiological Protection (ICRP) and the International Commission on Radiation Units and Measurements (ICRU), to assure uniformity in PAHO's efforts to promote international standards.

The Radiological Health Unit was transferred from the Environmental Health Division to the Disease Prevention and Control Division in mid-1979, and soon after, Gomez Crespo left PAHO. The responsibilities of both the Regional Advisor in Radiological Health and the Regional Advisor in Radiation Physics were entrusted to Hanson. The Radiological Health Unit was now dealing with radiation medicine (diagnostic radiology, radiation therapy, and nuclear medicine) as well as protection from radiation hazards from any source.

In the area of diagnostic radiology, efforts focused on developing the simplified X-ray system. In 1980 a commitment was obtained from the General Electric Company to provide four prototypes of their new "Technamatic" machine for a field trial in Latin America. This was an updated version of Chamberlain's invention. The new machines incorporated an improved tube stand and an advanced inverter type of "multipulse" X-ray generator. Since Chamberlain had purposely left the name "Technamatic" in the public domain (without trademark protection), General Electric used the name because it sounded innovative. PAHO selected Colombia to receive the four machines since that country had an active primary care program. The machines were delivered in 1983, and the successful field trial was concluded in 1984.

In 1980, in collaboration with the InterAmerican Social Security Research Center (Centro Interamericano de Estudios de Seguridad Social, CIESS), a seminar was held in Mexico City to assess the status of diagnostic radiology in the Region of the Americas. Also in 1980 the results of a survey of Spanish-language teaching materials for $\mathrm{X}$-ray technologists that had been initiated the year before were published by PAHO. In 1981, in collaboration with Member States and the Inter-American College of Radiology, a rapid assessment of the radiological health situation was conducted by the Radiological Health Unit, using questionnaires covering diagnostic radiology, radiotherapy, nuclear medicine, and radiation protection. The production of training materials for technologists was promoted by the Radiological Health Unit through cooperation with other PAHO technical units in an international workshop on the training of middlelevel technicians held at PAHO Headquarters in Washington, D.C., in 1981.

In the radiotherapy area, the IAEA/WHO Postal Dose Intercomparison Program for cobalt-60 teletherapy machines was gradually expanded, with an average of 60 radiotherapy centers per year being included over the 1979-1986 period. In 1980, PAHO provided follow-up technical cooperation, through visits by a radiation physicist to identify and correct errors in those radiotherapy centers where a deviation of greater that $5 \%$ between their reported measurements and the actual values measured in the IAEA laboratory had been found. This was the first time that such on-site follow-up was provided, a practice that both PAHO and the IAEA have continued to this date.

In the area of nuclear medicine, in collaboration with the USPHS Bureau of Radiological Health and the Federated Council of Nuclear Medicine 
Organizations, the Radiological Health Unit organized an international symposium on quality assurance, which was held in April 1981 at PAHO Headquarters, with 200 participants. The purpose was to review the status of nuclear medicine and to develop minimum standards for quality assurance programs. PAHO also collaborated in organizing a workshop on quality assurance for in vivo procedures in Santa Fe de Bogotá, Colombia (May 1981), and helped the IAEA and the Brazilian Association of Medical Physicists (Associação Brasileira de Física Médica, ABFM) organize a workshop on quality assurance in São Paulo, Brazil (September 1981). Again in collaboration with the USPHS Bureau of Radiological Health and the Federated Council of Nuclear Medicine Organizations, in 1982 PAHO hosted the International Symposium on the Developing Role of Short-Lived Radionuclides in Nuclear Medical Practice. With the same partners, PAHO also hosted the following symposia: Single Photon Ultrashort-Lived Radionuclides in Medical Practice (1983), Clinical Applications of Radionuclide Studies of the Brain (1984), and The Role of NonInvasive Imaging Modalities in Clinical DecisionMaking: Coronary Artery Disease (1985).

In radiation protection, the collaborative efforts of $\mathrm{PAHO}$ and the national radiation protection services of Argentina, Colombia, and Mexico resulted in the publication of Volume I of the revised Manual básico de protección radiológica [Basic Manual on Radiation Protection] by the Ministry of Health of Colombia. In collaboration with the Brazilian Institute of Radiation Protection and Dosimetry (Instituto de Radioproteção e Dosimetria, IRD) and with support from the U.S. Department of Energy, PAHO organized the Regional Seminar on Radiation Accidents and Procedures for Managing Irradiated Persons, which was held in Itaipava, Brazil, in December 1981. Seven years later, when a cesium-137 contamination accident occurred in Goiânia, Brazil, the Brazilian authorities were firmly in control of the situation and, using both national and local experts, skillfully handled the aftermath.

\section{3-1994, PASB DIRECTOR CARLYLE GUERRA DE MACEDO}

Soon after Carlyle Guerra de Macedo became the Director of the PASB in 1983, PAHO Headquarters staff members were assembled into groups for an introspective analysis that covered a period of several months. Shortly after, the function of program coordinator was created in the various PAHO technical divisions and continued until 2003.
From 1983 until 1987, the PAHO radiological health program continued on its main course, with radiation medicine (diagnostic radiology, radiation therapy, and nuclear medicine) and radiation protection being its major components.

A survey conducted by the Radiological Health Unit in 1983-1984 in cooperation with the health authorities of Argentina, Brazil, Colombia, Costa Rica, the Dominican Republic, Ecuador, Mexico, and Nicaragua showed that the use of X-ray equipment for diagnosis was low in small hospitals (ranging from $1 \%$ to $5 \%$ of patients) as compared to referral hospitals, where $20 \%$ to $30 \%$ of patients underwent an X-ray examination. This reinforced the priority given by $\mathrm{PAHO}$ and $\mathrm{WHO}$ to basic radiology at the Regional and global levels.

Four basic X-ray machines manufactured by the Siemens Corporation were delivered to Nicaragua in 1984 and, with the collaboration of WHO Headquarters staff (radiologist Eero Lehtinen), a field trial was conducted. In 1985, two machines manufactured by the Phillips Corporation were installed for a field trial in Chile. Results again demonstrated that with a short training period and proper supervision, excellent radiographs could be produced by local hospital staff.

In the radiotherapy area, efforts were made by the Radiological Health Unit to extend and improve the IAEA/WHO Postal Dose Intercomparison Program, following the recommendations of a working group meeting of the SSDL directors hosted by the M. D. Anderson Hospital in Houston in 1982. However, the results remained essentially the same, with only $60 \%$ of participating centers meeting the standard criteria of a deviation of $5 \%$ or less. In 1983 a key meeting, the First International Symposium on Quality Assurance in Radiation Therapy: Clinical and Physical Aspects, was held at PAHO Headquarters in Washington, D.C., with the collaboration of radiological societies from Europe, Latin America, and the United States and government institutions. The participants reviewed experiences in radiation therapy from around the world, and a consensus was reached concerning minimal as well as optimal standards for both clinical and physical aspects of quality assurance. The proceedings were published by Pergamon Press in 1984 on behalf of the co-organizers of the meeting (6).

During 1984 and 1985, assistance was provided to Argentina in a successful effort that resulted in the production of a cobalt- 60 teletherapy machine within the country. With PAHO's collaboration, Neutron Products, a United States company that refurbished used cobalt- 60 units, provided valuable technical assistance to Argentine institutions. These included the Ministry of Health, the 
Atomic Energy Commission, and the Institute of Applied Research in Bariloche, which subsequently collaborated in designing and manufacturing the Argentine machine.

In the area of nuclear medicine, PAHO, in collaboration with the WHO Collaborating Center in Nuclear Medicine in Danbury, Connecticut, United States, launched a new program for evaluating the quality of nuclear imaging procedures in 1983, using specially designed "phantoms" that could be mailed. Designed by the American College of Pathologists, the phantoms simulated various human organs as required for the relevant nuclear imaging procedure.

In radiation protection, assistance was provided to 20 countries from 1983 to 1986, through visits by the PAHO regional advisor and consultants, on legislation, organization of services, radiation measurements, radiation accidents, shielding calculations, and training.

In April 1987, Hanson was invited to become the Chief of Radiation Medicine at WHO Headquarters in Geneva, Switzerland, and resigned from PAHO. In March 1988, Cari Borrás took over the position of Regional Advisor in Radiological Health at PAHO Headquarters in Washington, D.C. A native of Spain, Borrás had a doctor of science degree from the University of Barcelona. She had prepared her thesis at Thomas Jefferson University in Philadelphia, Pennsylvania, as a Fulbright scholar. By the time she joined PAHO she had considerable international experience.

From 1988 to 1994, under Director Macedo's administration, Borrás continued PAHO's technical cooperation. She worked at both the Regional and country levels. Her tasks included data collection and situation analysis; revision and development of standards and guidelines; preparation and distribution of publications; consultations in radiation medicine and in radiation protection; assessment of policies and resources for radiology services coverage and for radiation protection programs; training activities, such as courses, seminars, and congresses; organization of and participation in scientific meetings; promotion and development of quality assurance programs; support to and collaboration with WHO and IAEA programs; initiation of a network of radiological physics centers, equipment donations, and loans; the removal of spent radioactive sources, and assistance in case of radiological emergencies $(7,8)$. The radiological health information collected from the countries was mainly published in PAHO's quadrennial Health in the Americas report $(9,10)$.

Efforts centered mainly on education. The PAHO Regional Advisor lectured in 40 country and/or Regional training events that were organized and/or cosponsored by PAHO. The most significant one was a hands-on course on physical dosimetry in radiation therapy held in San Antonio, Texas, in August 1988, which was attended by 45 Latin American medical physicists. The event was cosponsored by the International Organization for Medical Physics (IOMP) and the medical physics societies of the United States (AAPM), Latin America (ALFIM), and Spain (SEFM), in collaboration with PAHO and the IAEA.

A different training approach was taken in developing and establishing the radiological physics centers, which were institutions that could provide in situ practical training in radiological physics to physicians, medical physicists, engineers, and technologists involved in diagnostic and therapeutic radiology services. The first center was established in Caracas, Venezuela, in 1993, and the second one was set up in Tegucigalpa, Honduras, in 1995.

Through the IAEA/WHO postal dose audits, which verified the accuracy of the calibration of high-energy radiotherapy units with TLDs, and through the quality assurance workshops on radiation therapy held during that period $(7,8)$, it was ascertained that the source strength of most cobalt60 units in Latin American and Caribbean countries was too low for effective radiotherapy treatments. In 1993, PAHO, in collaboration with WHO, the IAEA, and the United Nations Industrial Development Organization, convened an advisory group meeting in Washington, D.C., to assess the situation and make recommendations concerning the problems of existing teletherapy units, including both cobalt-60 units and current linear accelerators. The proceedings of the meeting, which were published by Los Alamos National Laboratory in December 1995 (11), also presented new alternative designs for teletherapy units.

Consultations with the countries of the Americas concerned radiation medicine and also radiation safety, including prevention, preparedness, and response in case of a nuclear accident or a radiological emergency. The most significant radiological accident during that period involved three workers in San Salvador, El Salvador, in February 1989, with a cobalt-60 industrial irradiator used for sterilizing medical products. Due to the high radiation doses that the workers received, one of them died and another had his legs amputated (12).

Other minor accidents or incidents involved discarded brachytherapy sources in several Caribbean countries in the early 1990s. Concerned about potential exposures, PAHO contracted a United States company, NSSI/Sources and Services, to de- 
contaminate the premises where needed, to condition the sources, and to transport the sources to the United States for safe storage.

To prevent radiological accidents and to improve the radiation safety infrastructure in its Member States, PAHO joined the Inter-Agency Committee on Radiation Safety (IACRS) in 1991 and strengthened its cooperation with $\mathrm{WHO}$ and the IAEA. In 1993, it cosponsored a workshop on radiation safety for Central America and the Caribbean. In 1994 the XXIV Sanitary Conference endorsed the International Basic Safety Standards for Protection against Ionizing Radiation and for the Safety of Radiation Sources (BSS) (13), which had been jointly prepared through the IACRS.

\section{5-2003, PASB DIRECTOR SIR GEORGE A.O. ALLEYNE}

In the year 2000, PAHO's radiological health activities became part of the Essential Drugs and Technology Program within the Division of Health Systems and Services. Borrás became the program's coordinator, while also continuing to be responsible for radiological health activities. PAHO presented guidelines on radiology services in a 1997 publication, Organization, Development, Quality Assurance and Radiation Protection in Radiology Services: Imaging and Radiation Therapy (14). The text, which described the organizational and technical aspects of radiology services, was aimed at political leaders, administrators, planners, and health professionals, as well as ministries of health, and was intended to help them allocate resources and determine technological configurations for the provision of decentralized radiology services under health sector reform.

Guidelines for patient radiation protection were given at the International Conference on the Radiological Protection of Patients in Diagnostic and Interventional Radiology, Nuclear Medicine and Radiotherapy, which was held in Málaga, Spain, in 2001 and cosponsored by the IAEA, the European Commission (EC), PAHO, and WHO (15). It was attended by 800 people, 17 of them partially subsidized by PAHO. In 2002 the IAEA Board of Governors approved an International Action Plan on the Radiological Protection of Patients, to be carried out in cosponsorship with the EC, $\mathrm{PAHO}$, and WHO. PAHO, along with several other international organizations, also cosponsored the IAEA's new requirements on preparedness and response for a nuclear or radiological emergency (16). $\mathrm{PAHO}$ also participated in an international conference on the management of radioactive waste from non-power applications, which was organized by the IAEA (17); joined the Inter-Agency Committee on Response to Nuclear Accidents (IACRNA); and became part of the Joint Radiation Emergency Management Plan of the International Organizations (18). PAHO also increased its radiation protection technical cooperation in the area of nonionizing radiation, providing advice on the health effects of electromagnetic fields (especially those of cellular telephones), lasers, microwaves, ultrasound, magnetic resonance, and ultraviolet light.

The educational activities continued. During that period the Regional Advisor lectured in 98 country and/or Regional training events that were organized and/or cosponsored by PAHO (19-21). Most of the courses were aimed at Member States of PAHO or WHO and dealt with the implementation of the BSS in medical practice. A training manual, consisting of 1200 slides, was developed by PAHO for the IAEA.

The radiological physics center in Tegucigalpa, Honduras, was coordinated by the Autonomous University of Honduras (Universidad Autónoma de Honduras), which signed an agreement with the Ministry of Health to carry out activities of joint interest, including a special degree program for radiation technologists. In 1997-1999, this center was partially subsidized, through $\mathrm{PAHO}$, by the Ministry of Health of Spain.

PAHO continued to provide support during this period to the World Health Imaging System for Radiography (WHIS-RAD). In the mid-1990s, it purchased 11 of these units and installed them in Haiti. In spite of the inherent reliability of the equipment, the services had serious problems because of lack of maintenance, poor X-ray technician training, and inadequate radiation protection measures. Other efforts to upgrade radiology services involved Belize, Chile, Dominica, Haiti, St. Kitts and Nevis, and Trinidad and Tobago.

Efforts to upgrade radiotherapy services were carried out in various countries of the Americas. In Colombia, a countrywide evaluation was conducted; in Honduras, remote-control low-dose rate brachytherapy was introduced; in Trinidad and Tobago, a completely new cancer treatment facility was planned; and in Panama, cobalt therapy was replaced by linear accelerators. Quality assurance programs in radiation therapy services continued to be promoted, mainly through the TLD IAEA/ WHO Regional postal dose audit. A meeting on this program for TLD program coordinators from the Region of the Americas was held in Santo Domingo, Dominican Republic, in July 1999.

If one of the participating Costa Rican facilities had acknowledged a significant deviation that had appeared for several years, it could have prevented the overexposure of 114 patients-many 
of them children-that occurred as a consequence of a miscalibration of a cobalt-60 unit. PAHO was asked to provide technical assistance, and a year later the IAEA carried out its own investigation. PAHO was also asked to investigate a radiotherapy overexposure incident that occurred in Panama, caused by the improper use of treatment planning software. The details of the Panama exposure are published in this issue of this journal, in a report by Borrás (22).

In November 2001 and April 2002, Costa Rica again asked $\mathrm{PAHO}$ to assess potential radiation overexposures, this time caused by one or two medical linear accelerators. No evidence of overexposures was found.

Recognizing the need for standards in medical radiation dosimetry, PAHO cosponsored an international symposium in 2002 on standards and codes of practice in medical radiation dosimetry (23). PAHO also promoted an accreditation program for radiotherapy services to be implemented in the countries of Latin America and the Caribbean.

In 1999 the radiological health program won the research competition convened by PAHO's Director, with the theme of "quality assessment of radiology services," and prepared the terms of reference for the submission of projects. Seven countries applied, and five of them (Argentina, Bolivia, Colombia, Cuba, and Mexico) were awarded a research contract, which involved medical physicists and radiologists in these countries. The results of this health services delivery research project are presented in this issue of this journal, in an article by Fleitas et al. (24).

In 2001 a Regional diagnostic radiology research program to evaluate the image quality and the average glandular dose in mammography units in countries of the Americas was undertaken by PAHO and the Inter-American College of Radiology, in collaboration with the IRD in Brazil, and the Center for Devices and Radiological Health (CDRH) in the United States. Data from 61 units in 11 Latin American and Caribbean countries were collected and analyzed. Eighty-eight percent of the units evaluated complied with the image quality requirement, and only $8.5 \%$ of all the units exceeded the dose limit for the average glandular dose. $^{5}$

\footnotetext{
5 Borrás C, Mota H, Skvarca JJ. Measurements of image quality and dose in 61 mammography units in 11 countries [conference presentation]. 89th Radiological Society of North America Scientific Assembly and Annual Meeting, 28 November-3 December 2004, Chicago, Illinois, United States. Abstract available at: http://rsna2003. rsna.org/rsna2003/VBK/conference/event_display.cfm?id=66601\& em_id=3107772. Accessed on 19 February 2006.
}

\section{TO THE PRESENT, PASB DIRECTOR MIRTA ROSAS PERIAGO}

In January 2003, Mirta Roses Periago, who had previously served for eight years as the Assistant Director of the PASB, was the first woman to become the Director of the PASB. Organizational changes were made, and the radiological health program was located in the Area of Technology and Health Services Delivery (THS), first within the Health Services Organization Unit and finally within the Unit of Essential Medicines, Vaccines, and Health Technologies. Regardless of its location, the radiological health program carries out its activities by interacting with numerous areas within PAHO, following the new management model implemented by Director Roses.

Pablo Jiménez joined PAHO in July 2002 as an associate professional expert and became the regional advisor of the radiological health program in January 2004. A physicist, Jiménez received the Spanish equivalent of a master of science degree in physics from the University of Madrid (Universidad Complutense de Madrid) in 1988, and a degree (equivalent to a medical specialty) in medical physics and radiation protection from Spain's Ministry of Health and Ministry of Education in 1996. The other professional who was working in the radiological health program at PAHO Headquarters during this period, as an associate professional officer, was Ileana Fleitas. A nuclear engineer from Cuba, she joined PAHO in February 2003 and returned to Cuba in February 2006, where she is now working as a PAHO staff member in the radiological health program.

The main activities since 2003 have included strengthening diagnostic imaging and radiotherapy services, promoting regulations to protect against both ionizing and non-ionizing radiation, and improving the countries' capacity to respond to radiological or nuclear emergencies. Emphasis has been placed on advising on technology management.

Concerning diagnostic imaging and radiation oncology services, currently around 150 high-energy radiotherapy units are checked annually in Latin America and the Caribbean through the IAEA/ WHO TLD postal dose audit. The evaluation of radiation therapy and diagnostic imaging services has been continued in the Bahamas, Costa Rica, Guyana, Nicaragua, and Panama.

Technical advice and assessment in technology management were provided for the incorporation of new technology in Argentina, Costa Rica, Cuba, El Salvador, Guatemala, Trinidad and Tobago, Uruguay, and Venezuela.

The radiological health program has also been very active in organizing, cosponsoring, and supporting educational activities at the national, 
Regional, and global levels. The program organized a workshop on clinical quality in radiation therapy in Montevideo, Uruguay, and two subregional training workshops on quality assurance in radiology services for radiographers and radiological technologists, one in San Salvador, El Salvador for radiological technologists from Central America, and the other in Guyana for radiographers and radiological technologists from the Caribbean. Within a project called Teaching the Teachers Initiative for Ultrasound Training in Latin America and the Caribbean, a total of 12 radiologists from 12 countries was selected to attend an intensive 12week training program during 2005 and 2006 at the Jefferson Ultrasound Research and Education Institute, which is located in Philadelphia and is one of the $\mathrm{PAHO} / \mathrm{WHO}$ Collaborating Centers. A total of six educational centers in ultrasound will be established in the Region by the end of 2007.

The most important international meetings, congresses, and conferences where the radiological health program was represented and where support was provided during this period were the XI Congress of the International Radiation Protection Association, in Madrid, Spain; the III Iberian Latin American and Caribbean Congress of Medical Physics, in Rio de Janeiro; the Regional CRILA Congress, in Lima; National Infrastructures for Radiation Safety: Towards Effective and Sustainable Systems, in Rabat, Morocco; and the VI and VII Regional Congresses of the International Radiation Protection Association, in Lima.

Concerning other activities, national regulations were evaluated and comments on them were sent to the Bahamas, Bolivia, Honduras, Panama, and Paraguay. A Regional compilation of the national regulations on non-ionizing radiation was completed; a radiation emergency exercise was executed jointly with the Organization of American States, in Barbados; a self-evaluation guideline to respond to radiological emergencies was prepared and sent to Peru; and a workshop for Andean countries on dangerous radioactive materials was held in Quito, Ecuador.

In addition, the PAHO radiological health program actively participates in two IAEA Regional cooperation agreements for Latin America and the Caribbean (Acuerdos Regionales de Cooperación para América Latina y el Caribe, ARCAL) dealing with radiology and the education of medical physicists. One of the strategic lines consists of the establishment of a formal agreement with the IAEA's Technical Cooperation Department, which will include a joint Regional project for $2007 / 2008$ to improve the quality of radiation therapy.

At the global level, the practice of co-sponsoring relevant IAEA publications continued. PAHO par- ticipated in the 2004 version of the Joint Radiation Emergency Management Plan of the International Organizations (18). It also attended the I and II Steering Panel Committee Meetings of the International Action Plan for the Radiological Protection of Patients, in Madrid, contributing to drafting the actions for 2006 and 2007 geared to promoting education and training, providing assistance, rendering services, fostering information exchange, and coordinating research in the areas of diagnostic and interventional radiology, nuclear medicine, and radiation therapy (25). PAHO also organized and hosted the XI Meeting of the IACRS, a distinction it had not held since 1992. It also continued participating in the IAEA Radiation Safety Standards Committee (RASSC) meetings and the WHO Radiation Emergency Medical Preparedness and Assistance Network (REMPAN). The PAHO radiological health program has now begun the process of revising the BSS.

\section{CONCLUSIONS}

PAHO's radiological health program has been in existence for nearly half a century. The program has focused on specific issues in keeping with the times, as well as on the priorities of PAHO's Member States. The latter have had at their disposal the most current scientific and professional knowledge and advice available, as well as a steady partner for continuously improving their national institutions.

As new discoveries and new challenges appear, the most important needs envisaged for the immediate future are: education and training in evaluating, incorporating, and utilizing new technologies; support for strengthening radiological diagnostic and therapeutic services; support for research on analyzing and evaluating outcomes; implementing ways to safeguard patients and staff, including strengthening regulations; and improving the capacity to respond to radiological and nuclear emergencies.

With the continuing confidence and support of PAHO's Member States, the PAHO radiological health program is expected to continue to respond to their needs.

\section{SINOPSIS}

\section{Historia del programa de radiología y radioprotección de la Organización Panamericana de la Salud}

El programa de radiología y radioprotección de la Organización Panamericana de la Salud (OPS) se estableció en 1960. En ese entonces, las superpotencias mundiales se en- 
frascaban en la carrera armamentista; hacian pruebas con armas nucleares en la atmósfera y los pueblos y gobiernos del mundo les temían a los efectos de la lluvia radiactiva. Además, se comenzaba a fomentar el uso pacífico de las radiaciones en la medicina, la investigación y la industria, por lo cual se necesitaba una protección adecuada contra estas nuevas formas de energía. Como se señaló en el Informe anual del Director de la OPS, los objetivos de ese nuevo programa de la Organización eran: 1) incentivar la adopción de reglamentos aplicables al uso de las radiaciones en consonancia con las recomendaciones de la Comisión Internacional de Protección Radiológica; 2) promover la enseñanza de la física médica y de la protección radiológica; 3) ayudar a desarrollar las aplicaciones de los radioisótopos en el diagnóstico, el tratamiento y la investigación médica; y 4) impulsar las investigaciones relacionadas con el uso de las radiaciones en la medicina, la salud pública y la veterinaria.

Durante casi medio siglo, el programa de radiología y radioprotección de la OPS ha centrado su atención en diversos temas, según las necesidades y prioridades de los Estados Miembros. Para ello siempre ha contado con personal altamente calificado capaz de asesorar a los ministerios de salud acerca de las politicas relacionadas con las aplicaciones sani- tarias de las radiaciones, y a las instituciones clinicas acerca de las modalidades radiológicas diagnósticas y terapéuticas más recientes. Como en sus inicios, el programa continúa prestando atención a las siguientes necesidades de la Región: la educación y capacitación del personal de radiología para que aprenda a evaluar, incorporar y utilizar con eficacia y seguridad las nuevas tecnologías; el apoyo gerencial y técnico para fortalecer los servicios radiológicos; el asesoramiento integral orientado a establecer o mejorar los programas gubernamentales de radioprotección, incluida la adopción de legislación y reglamentación para el control de las radiaciones ionizantes y no ionizantes; el fomento de la investigación para analizar y definir prioridades; y el fortalecimiento de la capacidad institucional con miras a responder a las emergencias radiológicas y nucleares. A pesar de que surgen nuevos retos a medida que se producen nuevos descubrimientos, el Programa de radiología y radioprotección de la OPS seguirá respondiendo a las necesidades de los Estados Miembros.

Palabras clave: prestación de atención de salud, radiología, protección radiológica, radioterapia, Organización Panamericana de la Salud, Américas.

\section{REFERENCES}

1. Pan American Health Organization. Annual report of the Director, 1960. Washington, D.C.: PAHO; 1961. (Official Document No. 38)

2. Pan American Health Organization. Annual report of the Director, 1962. Washington, D.C.: PAHO; 1963. (Official Document No. 50).

3. International Atomic Energy Agency. Manual of dosimetry in radiotherapy. Vienna: IAEA; 1970. (Technical Report Series No. 110).

4. Iżewska J, Vatnitsky S, Shortt KR. Postal dose audits for radiotherapy centers in Latin America and the Caribbean: trends in 1969-2003. Rev Panam Salud Publica. 2006;20(2/3):161-72.

5. Palmer PES. Radiology and primary care. Washington, D.C.: Pan American Health Organization; 1978. (Scientific Publication No. 357).

6. Hanks G, Svensson G, eds. Quality assurance in radiation therapy: clinical and physical aspects. Proceedings of the First International Symposium on Quality Assessment in Radiation Oncology, Washington, D.C., 8-10 June, 1983. New York: Pergamon Press; 1984. (International Journal of Radiation Oncology, Biology Physics, Volume 10, Supplement 1).

7. Pan American Health Organization. Report of the Director: quadrennial 19861990, annual 1989. Washington, D.C.: PAHO; 1989 (Official Document No. 234).
8. Pan American Health Organization. Report of the Director: Quadrennial 19901993; annual 1993. Washington, D.C.: PAHO; 1993. (Official Document No. 262).

9. Pan American Health Organization. Health conditions in the Americas: 1990 edition. Washington, D.C.: PAHO; 1990. (PAHO Scientific Publication 524).

10. Pan American Health Organization. Health conditions in the Americas: 1994. Washington, D.C.: PAHO; 1994. (Scientific Publication No. 549)

11. Borrás C, Stovall J, eds. Design requirements for megavoltage $\mathrm{X}$-ray machines for cancer treatment in developing countries: report of an Advisory Group Consultation. Los Alamos: Los Alamos National Laboratory; 1995. (LA-UR-95-4528).

12. International Atomic Energy Agency. The radiological accident in San Salvador. Vienna: IAEA; 1990

13. Food and Agriculture Organization of the United Nations, International Atomic Energy Agency, International Labour Organisation, Nuclear Agency of the Organisation for Economic Co-operation and Development, Pan American Health Organization, World Health Organization. International basic safety standards for protection against ionizing radiation and for the safety of radiation sources. Vienna: IAEA; 1996. (Safety series 115).

14. Borrás C, ed. Organization, development, quality assurance and radiation protection in radiology services: imag- ing and radiation therapy. Washington, D.C.: Pan American Health Organization; 1997.

15. International Atomic Energy Agency. Radiological protection of patients in diagnostic and interventional radiology, nuclear medicine and radiotherapy. Proceedings of an international conference held in Málaga, Spain, 26-30 March 2001. Available from: http:/ / www-pub. iaea.org/MTCD/publications/PDF/ Pub1113_scr/Pub1113_scr1.pdf [Web site]. Accessed 15 February 2006.

16. International Atomic Energy Agency. Preparedness and response for a nuclear or radiological emergency. Vienna: IAEA; 2002

17. Borrás $\mathrm{C}$, Rudder DDG, Porte J, Archibald A, Miller $\mathrm{C}$, Lokerse $\mathrm{AF}$, et al. Radioactive waste management in British and Dutch Caribbean countries. In: Proceedings, International Conference on Management of Radioactive Waste from Non-Power Applications-Sharing the Experience. Vienna: IAEA; 2002. Pp. 84-89. (IAEA-CN-87/91).

18. International Atomic Energy Agency. Joint Radiation Emergency Management Plan of the International Organizations. Vienna: IAEA; 2004.

19. Pan American Health Organization. Leading Pan American health: quadrennial report of the Director 1994-1997. Washington, D.C.: PAHO; 1998. (Official Document No. 287). 
20. Pan American Health Organization. Charting a future for health in the Americas. Quadrennial report of the Director. Washington, D.C.: PAHO; 2002. (Official Document No. 306).

21. Pan American Health Organization. Health in the Americas: 2002 edition. Washington, D.C.: PAHO; 2002. (PAHO Scientific and Technical Publication No. 587).

22. Borrás C. Overexposure of radiation therapy patients in Panama: problem recogni- tion and follow-up measures. Rev Panam Salud Publica. 2006;20(2/3); 173-87.

23. Borrás $C$, Rudder D, Jiménez P. Use of imaging techniques in radiation oncology. In: International Atomic Energy Agency. Standards and codes of practice in medical radiation dosimetry. Proceedings of an international symposium, Vienna, 25-28 November 2002. Vienna: IAEA; 2003.

24. Fleitas I, Caspani CC, Borrás C, Plazas MC, Miranda AA, Brandan ME, et al.
La calidad de los servicios de radiología en cinco países latinoamericanos. Rev Panam Salud Publica. 2006;20(2/3): $113-24$.

25. International Atomic Energy Agency. International Action Plan for the Radiological Protection of Patients. Available from: http://www-ns.iaea.org/downloads/ $\mathrm{rw} /$ radiation-safety/PatientProtAction Plangov2002-36gc46-12.pdf [Web site]. Accessed 15 February 2006 


\section{ARTÍCULOS E INFORMES ESPECIALES}

\section{ARTICLES AND SPECIAL REPORTS}


